\title{
Effectiveness of Mindfulness Based Cognitive Therapy on Loneliness and Rumination of Veterans' Spouses
}

\section{ART I C L E INF O}

\section{Article Type}

Original Research

\section{Authors}

Talebi A. ${ }^{1} M A$,

Zarnaghash M.*1 $\mathrm{PhD}$

How to cite this article
Talebi A, Zarnaghash M. Effective-
ness of Mindfulness Based Cognit-
ive Therapy on Loneliness and
Rumination of Veterans' Spouses.
Iranian Journal of War \& Public
Health.2020;12(1):29-34.

\begin{abstract}
A B S T R A C T
Aims Veterans' families, especially their wives, are at high risk for mental and psychological injuries that should be noticed to them. The aim of present study was to investigate the effectiveness of mindfulness based cognitive therapy on loneliness and rumination of veterans' spouses.

Materials \& Methods In this experimental study with pretest-posttest design with control group, 22 veterans' spouses of Shiraz city in 2018 were selected by purposive sampling method and randomly assigned into case and control groups (11 subjects in each group). Participants in both groups completed the DiTommaso's loneliness questionnaire and the Nolen-Hoeksema's rumination questionnaire. The case group was then subjected to mindfulness-based cognitive therapy intervention during 8 sessions of 120-150 minutes. After group therapy on the case group, the post-test was performed on both groups. Data were analyzed by SPSS 20 software, using dependent and independent t-tests.

Findings In case group, significant changes in the sense of loneliness and rumination scales were observed in the post-test compared to the pre-test $(\mathrm{p}=0.0001)$. However, no significant changes were observed in the control group. There was also a significant difference between the case group and the control group in the sense of loneliness $(\mathrm{p}=0.01)$ and rumination $(\mathrm{p}=0.001)$.
\end{abstract}

Conclusion Mindfulness-based cognitive therapy is an effective strategy to reducing sense of loneliness, and rumination in veterans' spouses.

Keywords Cognitive Therapy; Mindfulness; Loneliness; Rumination; Veterans; Spouses
${ }^{1}$ Psychology Department, Psychology \& Educational Sciences Faculty, Marvdasht Branch, Islamic Azad University, Marvdasht, Iran

\section{*Correspondence}

Address: Marvdasht Branch, Islamic Azad University, 3 km of MarvdashtPersepolis Boulevard, Fars, Iran. Postal code:7371113119 Phone: +98 (71) 43112201 Fax: +98 (71) 43311172 mzarnaghash@miau.ac.ir

\section{Article History}

Received: April 22, 2019

Accepted: January 18, 2020

ePublished: March 17, 2020

\section{CITATION L INKS}

[1] Studing the issues of veteran's wives ... [2] Mortality and morbidity after excessive stress ... [3] War and remmembrence ... [4] Elements and structure of medical ethics ... [5] The comparison between mental health ... [6] Investigation of personality traits of wives of spinal cord ... [7] Aspects of marital satisfaction among veterans' ... [8] Mindfulness training as a clinical intervention: a conceptual ... [9] Mindfulness-based treatments ... [10] Mindfulness-based interventions in context: past, present ... [11] Post-translational modifications distinguish ... [12] The effectiveness of mindfulness-based stress reduction ... [13] Measurement and validity characteristics ... [14] Attachment styles, social skills and loneliness in young ... [15] Mindfulness-based stress reduction for chronic ... [16] Chronic loneliness within an attachment framework ... [17] Responses to depression and their effects ... [18] Mindfulness-based interventions for the treatment ... [19] The comparitive efficacy of cognitive- behavior therapy and ... [20] The effectiveness of mindfulness-based group cognitive therapy ... [21] The effectiveness of mindfulness training on reducing rumination ... [22] Effectiveness of mindfulness-based cognitive therapy on ... [23] The influence of mindfulness-based cognitive therapies on loneliness ... [24] Mindfulness training for loneliness among Chinese college students ... [25] The effect of mindfulnessbased cognitive therapy on depression ... 
تامين مراقبت از بيمار مزمن توسط اعضاى خانواده منجر به احساس

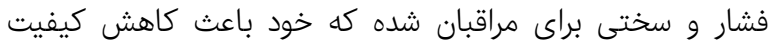

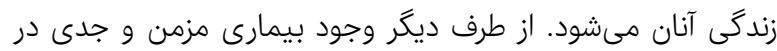

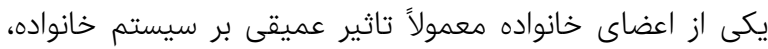

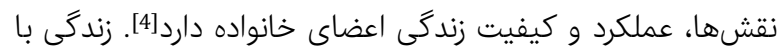

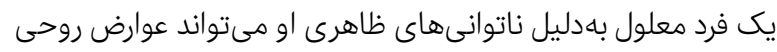

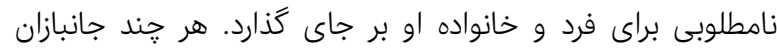

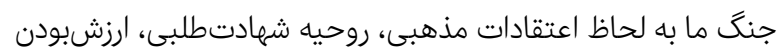

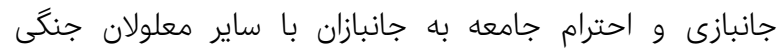

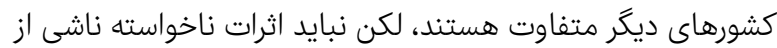

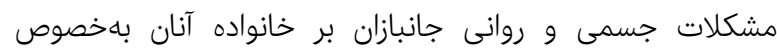

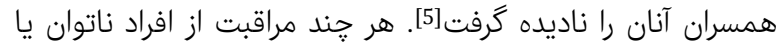

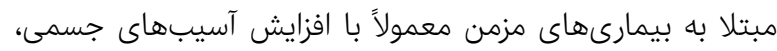

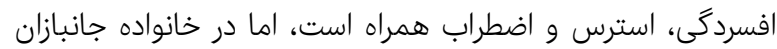

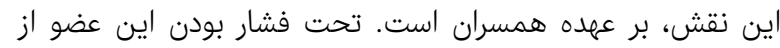
خانواده كه نقش محورى دارد، بيش از سايرين سلان سلامتى، رفاه

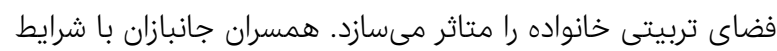

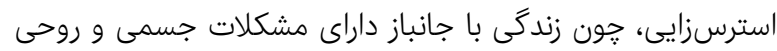

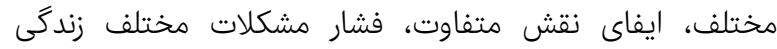

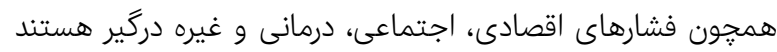

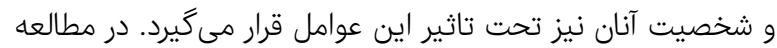

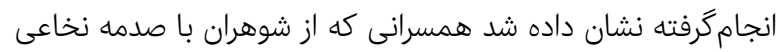

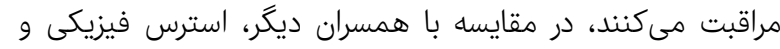

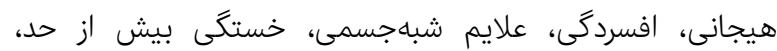

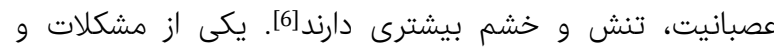

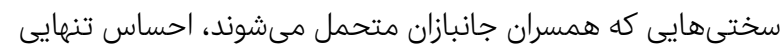

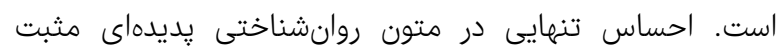

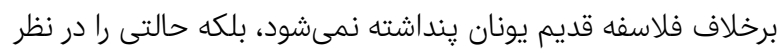

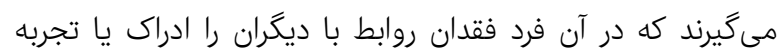

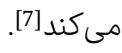

يكى از درمانهايى كه به نظر مىرسد مىتواند به فرد كمك كند كه

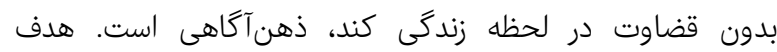

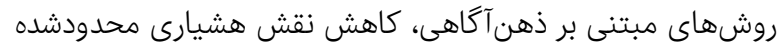

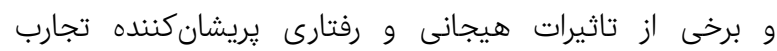

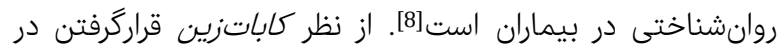

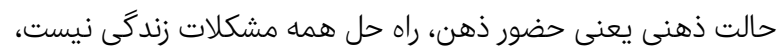

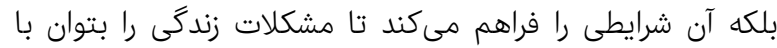

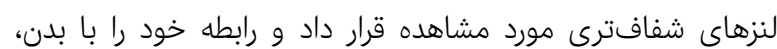

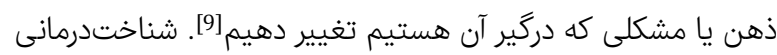

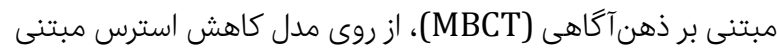

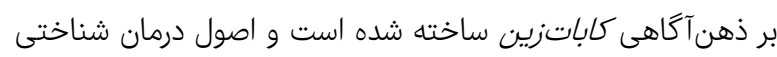
به آن اضافه شده است. اين نوع شناخت آدرمانى شانى شامل مديتيشنه

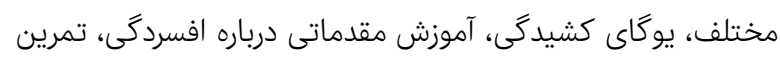

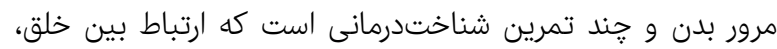

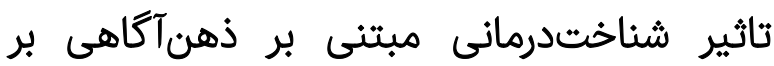
احساس تنهايى و وسواس فكرى همسران جانبازان

على طالبى MA

كَره روانشناسى، دانشكده علوم تربيتى و روانشناسى، واحد مرودشت، دانشگاه آزاد اسلامى، مرودشت، ايران دانش

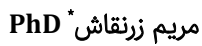
كروه روانشناسى، دانشكده علوم تربيتى و روانشناسى، واحد مرودشت، دانشگاه آزاد اسلامى، مرودشت، ايران

קكيده

اهداف: خانواده جانبازان بلهويزه همسران آنان در معرض آسيبهاى روحى و ور روانى

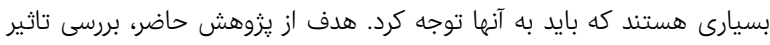

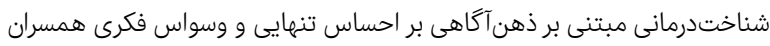

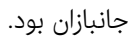

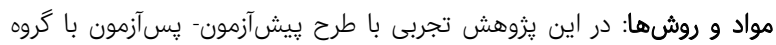

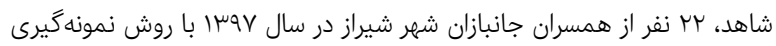

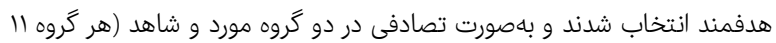

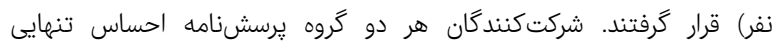

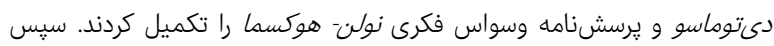

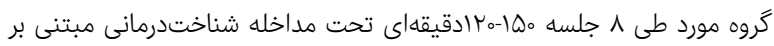

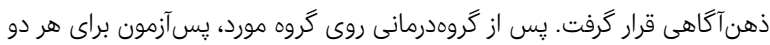

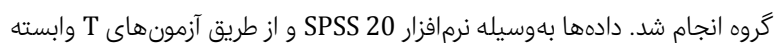
و Tستقل تجزيه و تحليل شدند.

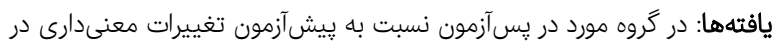

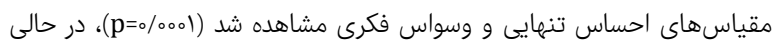

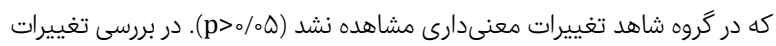

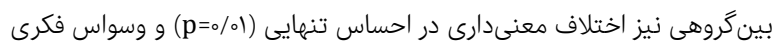
(p=o/\%ol)

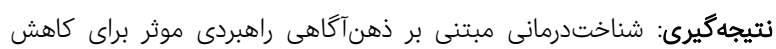

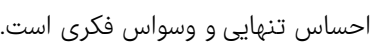

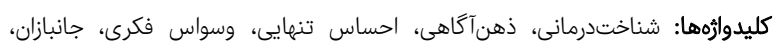
همسران

تاريخ دريافت: - تاريخ

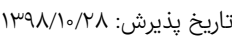

"نويسنده مسئول: باترش:

\section{مقدمه - مقه}

جنگ تحميلى بهعنوان يك عامل فشارزاى شديد، محورهاى متعدد

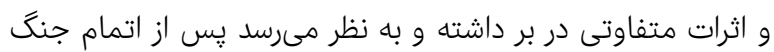

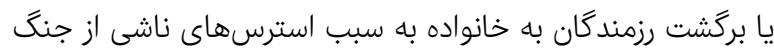

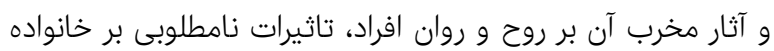
بهويزه همسران كذاشته است. تجارب بالينى زيادى نشان دادي داده است آتران

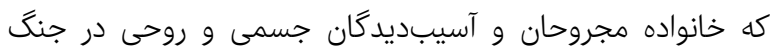
خصوصاً همسران آنان، از مشكلات روانى رنج مى ربرندان

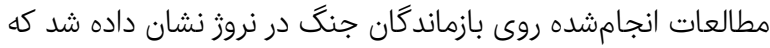

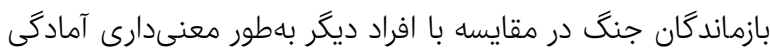
ابتلا به بيمارى را دارند [2,3]. 


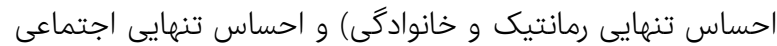

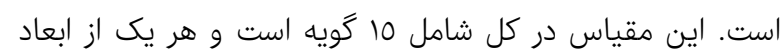

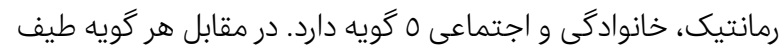

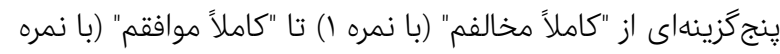

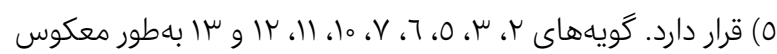

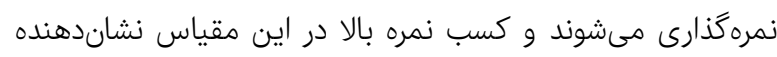
احساس تنهايى بيشتر در هر يك از ابعاد است.

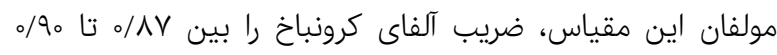

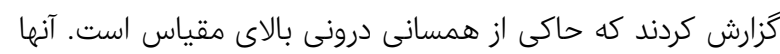

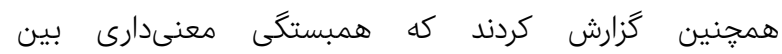

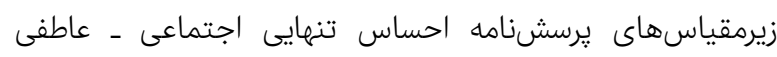

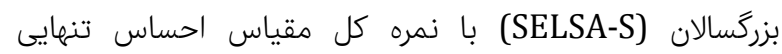
و زيرمقياسهاى برسشنامه ادراك دلبستخى به والدين (UCLA)

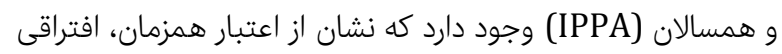

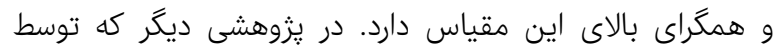

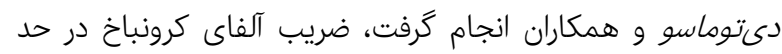

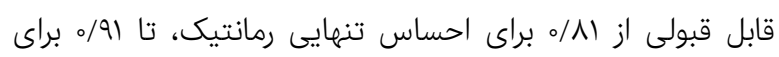

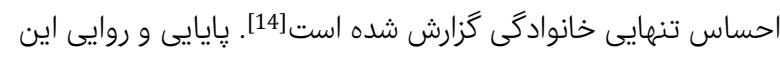

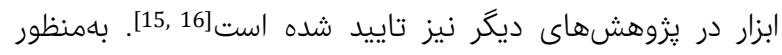

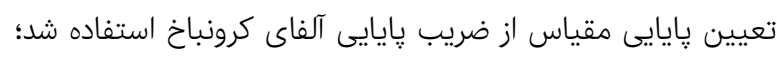

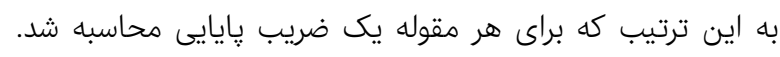
ضريب يايايى حاصله براى ابعاد احساس تنهايى رمانتيك، احساس

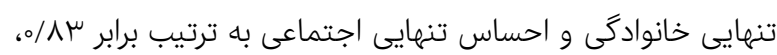

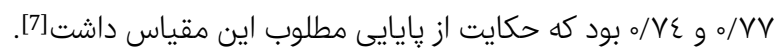

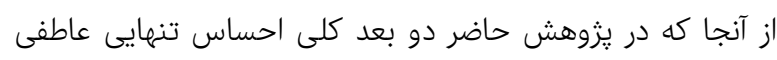

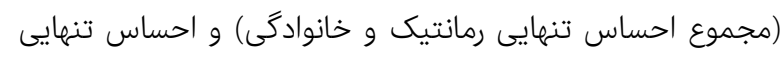

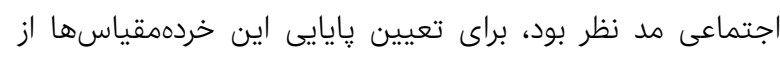

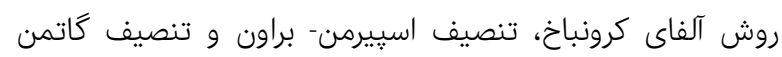

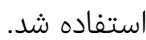

r- برسشنامه وسواس فكرى نولن- هوكسما: براى اندازمخيرى

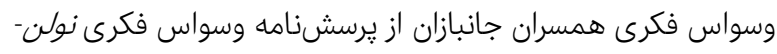

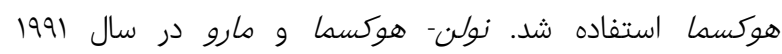

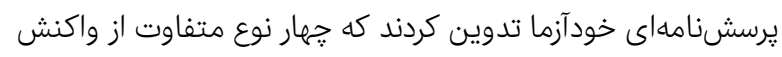

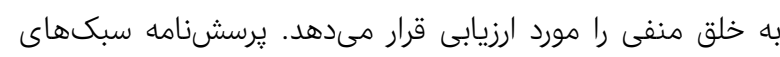

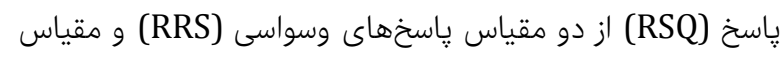

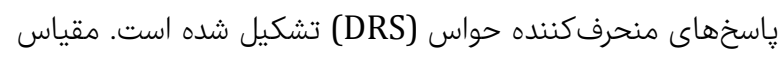

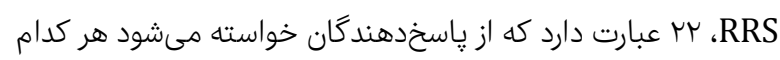

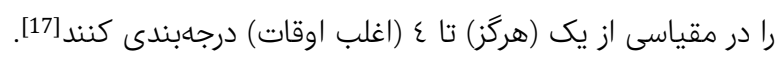

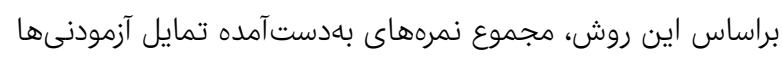

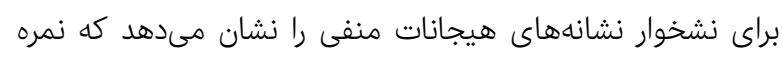

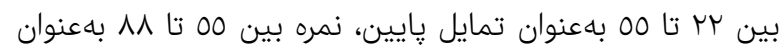

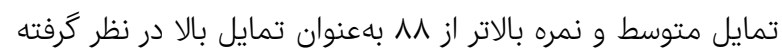

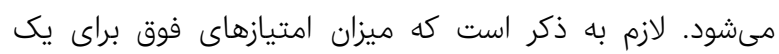

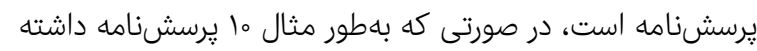

افكار، احساس و حسهاى بدنى را نشان مىدهد. در حالتهاى

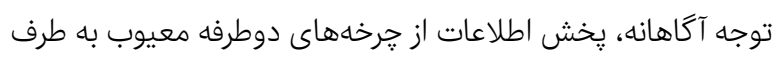

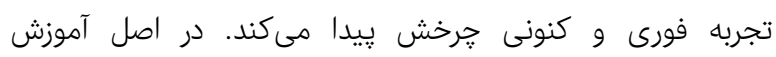

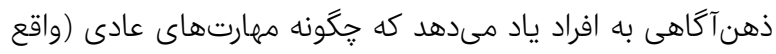

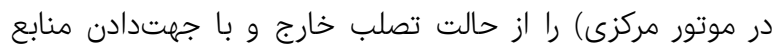

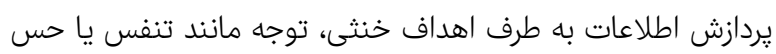
لحظه شرايط را براى تغيير آماده كنند [10].

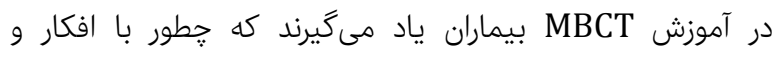

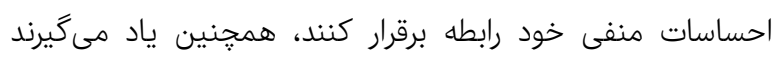

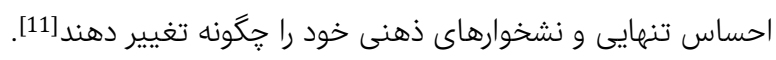

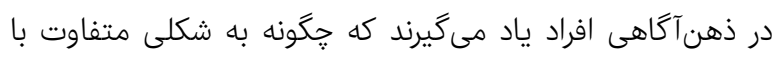

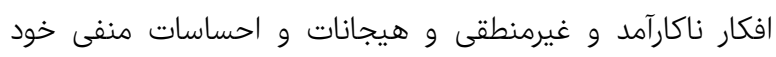

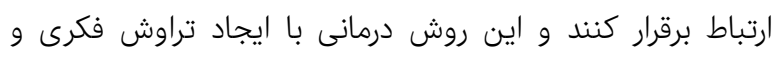

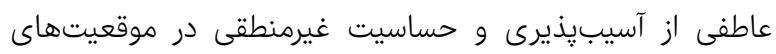

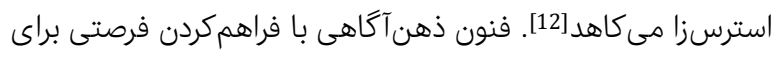

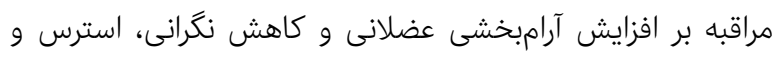

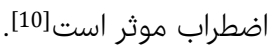
با توجه به اين كه اثربخشى ذهن آكاهى إنى بر اين تركيب از متغيرها

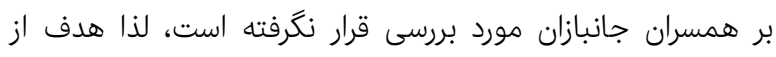

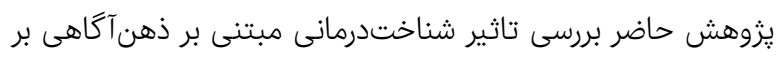
احساس تنهايى و وسواس فكرى همسران جانبازان بود.

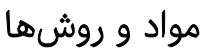

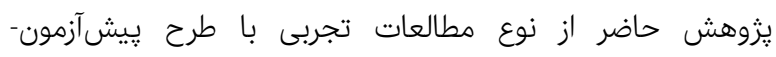

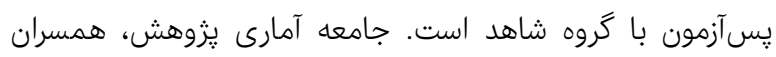

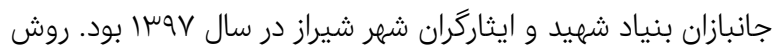

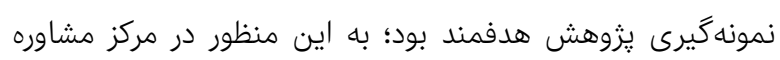

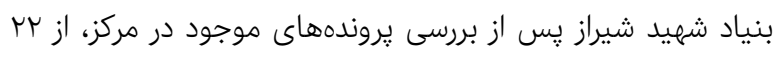

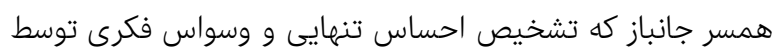

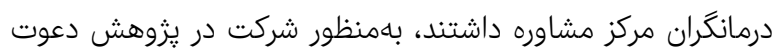

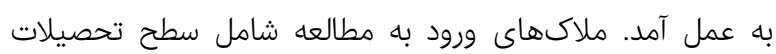

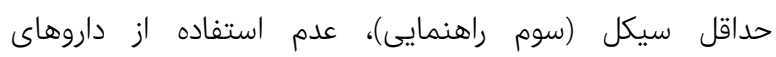

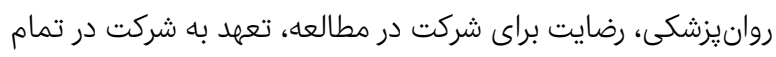

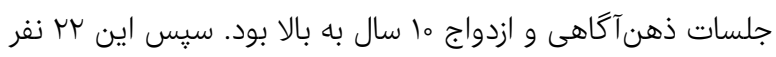
بهاطور تصادفى به دو گروه النفره مورد و شاهد تاهد تقسيم شدند.

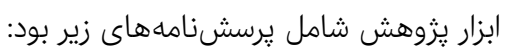

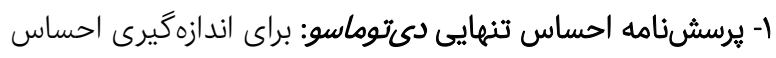

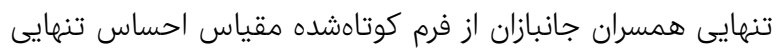

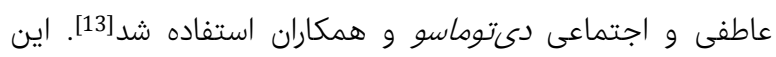

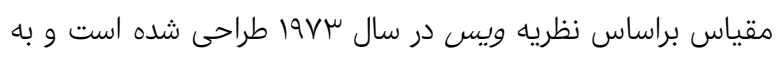

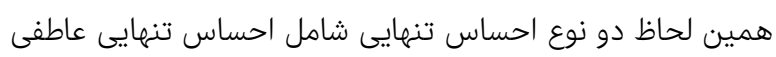

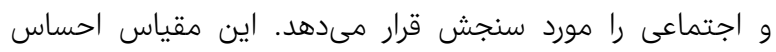

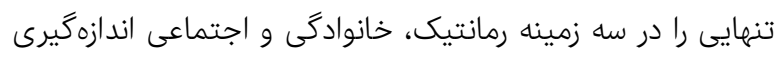
مىكند و شامل دو بعد كلى احساس تنهايى عاطفى (مجموع 
شد و به مراجعان اطمينان خاطر داده شد كه اطلاعات آنان محرمانه

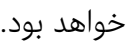

تجزيه و تحليل دادهها توسط نرمافزار آمارى SPSS 20 كورد

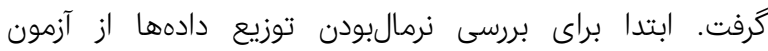

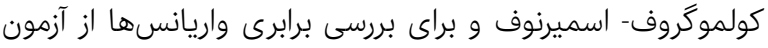

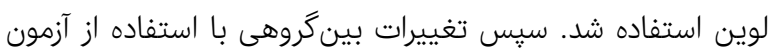

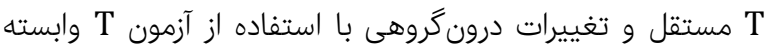

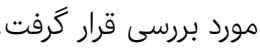

يافتهها

دامنه سنى شركت كنند

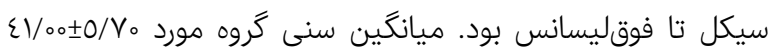

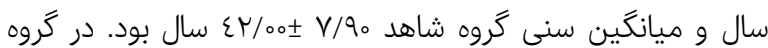

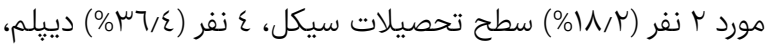

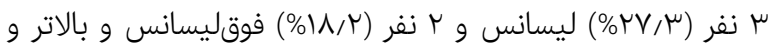

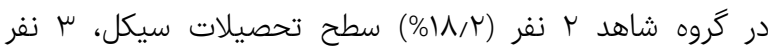

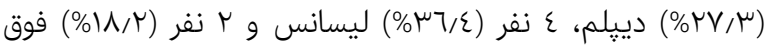

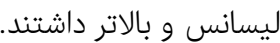

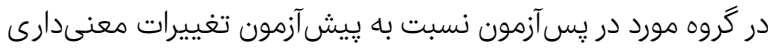

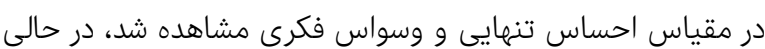

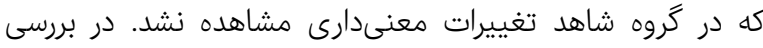

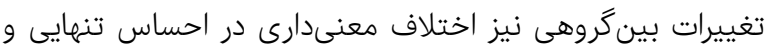

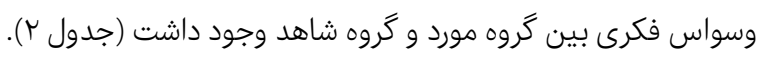
جدول r) مقايسه بينكروهى و درونَّروهى ميانكَين آمارى نمرات احساس

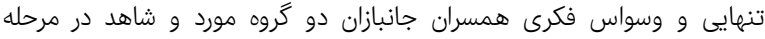
بيشآزمون و يسآزمون

\begin{tabular}{|c|c|c|c|c|}
\hline \multicolumn{2}{|c|}{ سطح معنىدارى } & \multirow{2}{*}{ بِ آزمون } & \multirow{2}{*}{\multicolumn{2}{|c|}{ پيشآزمون }} \\
\hline بينگروهى & درون كروهى & & & \\
\hline \multirow{3}{*}{$\%$} & & & \multicolumn{2}{|c|}{ احساس تنهايى } \\
\hline & $\% \% 001$ & $\mu V / \Delta K_{ \pm} \kappa / V \varepsilon$ & $\ll \& / \Delta \circ \pm 0 / \wedge q$ & كروه هورد \\
\hline & or & $\mid k \& / \varepsilon_{0} \pm Y Y / / \mu$ & $K \& / \varphi_{0} \pm V Y / 9 \mid$ & كروه شاهد \\
\hline \multirow{3}{*}{$\% / 001$} & & & \multicolumn{2}{|c|}{ وسواس فكرى } \\
\hline & $\%$ \%०01 & $Y Y / T \circ \pm K \Delta / \Delta F$ & $K_{N / / K_{\circ} \pm \varepsilon \mu / T Y}$ & كروه مورد \\
\hline & 促 & $\omega_{0} / \mu_{0 \pm 0} / 9 \Lambda$ & $<q / \mu \circ \pm 0 q / q \mid$ & كروه شاهد \\
\hline
\end{tabular}

بحث

نتايج يزوهش حاضر نشان داد كه آموزش كروهى شناختدرمانى

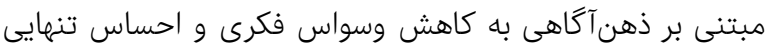

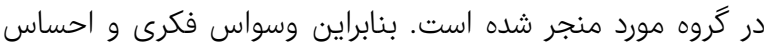

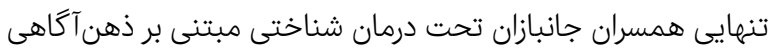

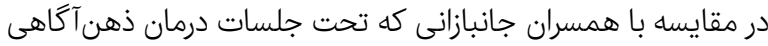

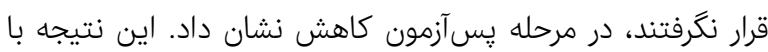

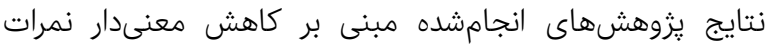

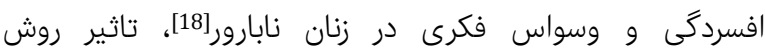

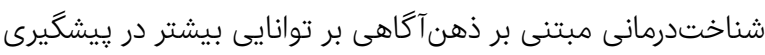

باشيم بايد امتيازها را ضربدر ها كنيم.

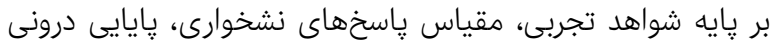

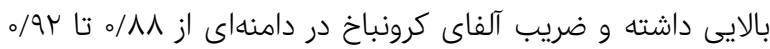

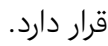
دو گروه مورد و شاهد در مرحله يِيشآزمون، يرسشنامه احساس

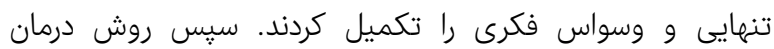

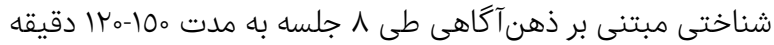

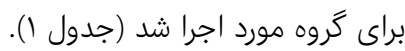

جدول () شرح جلسات شناختدرمانى مبتنى بر ذهن آكًاهى

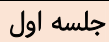
معارفه اعضا و درمانكً، توضيح كليات و مبانى ذهن آكاهى و اثربخشى آن، شرح

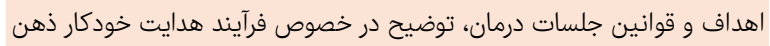

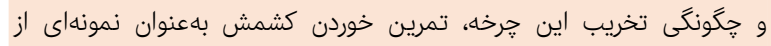

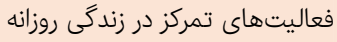

جلسه دوم بررسى تكاليف هفته قبل، تمرينات تنفسى بلهعنوان شيوهاى براى تنفس عميق،

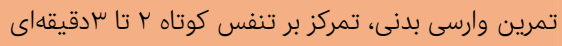

جلسه سوم

خلاصهاى از جلسه قبل و بررسى مشكل، راهرفتن آكاهانه (با حالت آرامش،

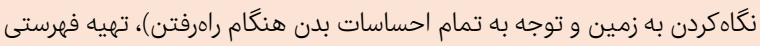

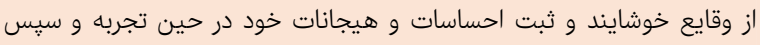

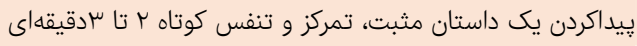

جلسه جهارم

بررسى تكاليف و خلاصهاى از جلسه قبل، اجراى تنفس عميق و ذهائ ذهن آكاهانه،

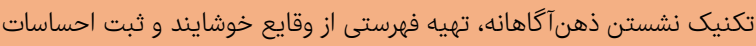

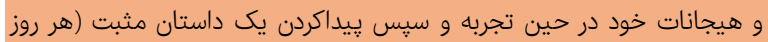
يك رويداد) جلسه ينجم رويل بررسى تكاليف هفته قبل، بحث و بررسى يِيرامون بازخورد تمرينات در اين جلسه

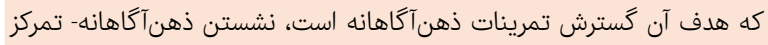

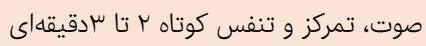
جلسه ششم

خلاصهاى از جلسه قبل و بررسى تكاليف انجامشده، اجراى مديتيشن افكار و

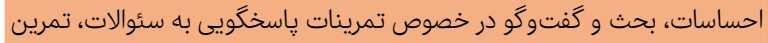

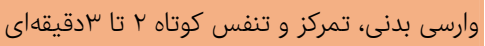
جلسه هفتم

بررسى تكاليف انجامشده، مرور تمرينات هفته قبل و رفع مشكل، توضيحات لازم

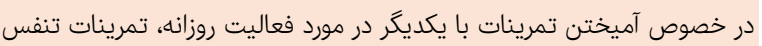

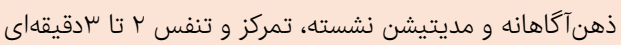

جلسه هشتم

بررسى تكاليف انجامشده، تمرين وارسى بدنى، جمعبندى نهايى، در بايان از آنها

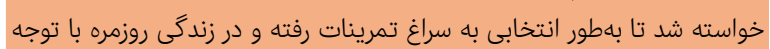

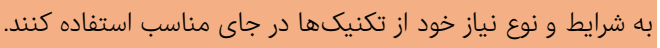

بعد از اتمام جلسات آموزشى، مرحله يِ آزمون براى هر دو گروه به

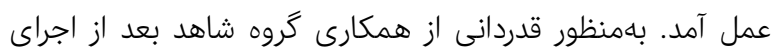

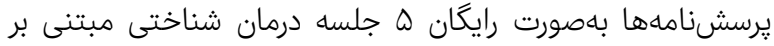

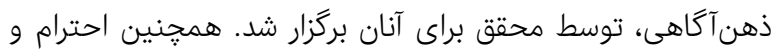
رعايت اصول اخلاقى نسبت به شركت كنندكان در جلسات درمان آندان اجرا 
تاثير شناختدرمانى مبتنى بر ذهن آكاهى بر احساس تنهايى و وسواس فكرى همسران جانبازان سبر

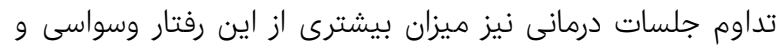
افكار وسواسى كاهش يابد. از عود افسردگى[19]، كاهش وسواس فكرى و افسردگى زنان در حال

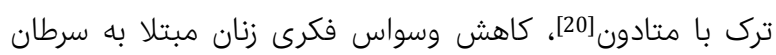

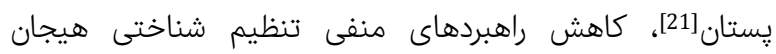

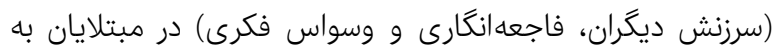

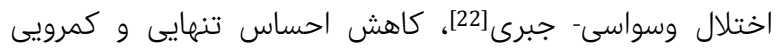

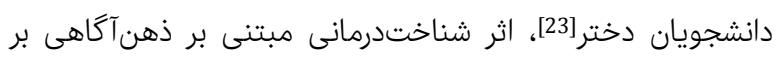

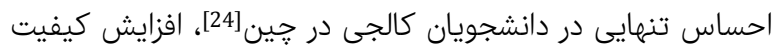

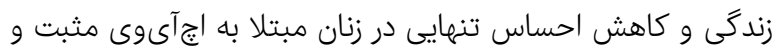

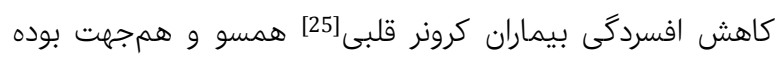

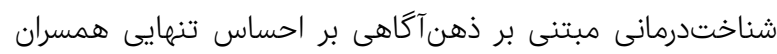

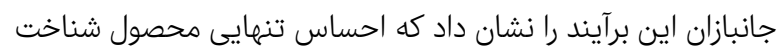

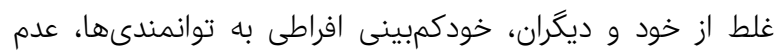

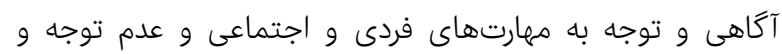

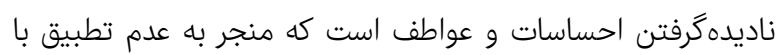

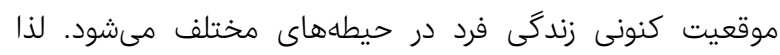
جلسات شناختدرمانى مبتنى بر ذهن آكاهى براى اين دسته از ازفي افراد

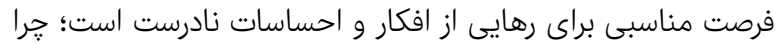
كه در روش شناختدرمانى مبتنى بر ذهن آكاهى بر مشاهدا

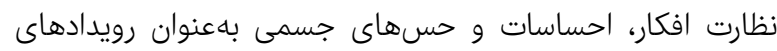

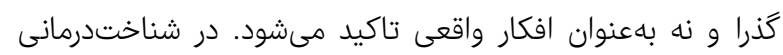

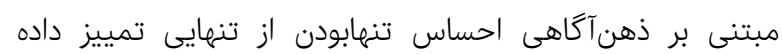

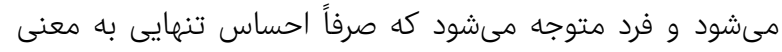

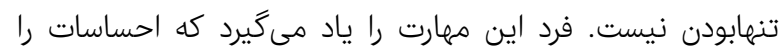

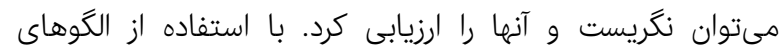

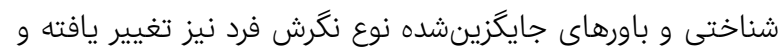

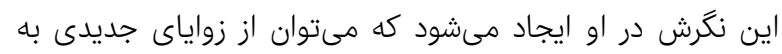

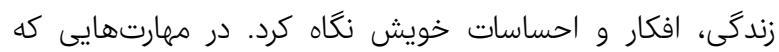
درمانجو كسب مىكند مىتواند از قضاوتهايى كه منجر به احساس

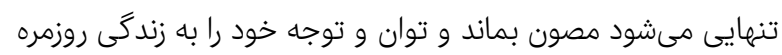

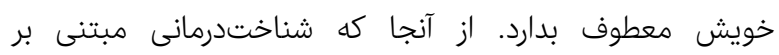
ذهن آكاهى موجب درك لحظه به لحظه رويدادها و اجازه ثبت آنها با هوشيارى كامل بدون تاثير انتظارات، علايق و سوكيرى دهاى دهاى

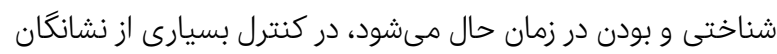

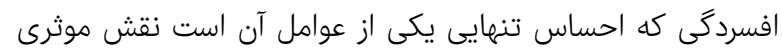

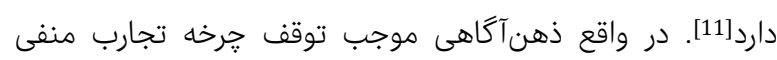

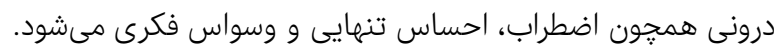
همانند ساير تحقيقات تجربى، اين مطالعه خالى از إن محدوديت نيست. در اين آزمون فقط از يرسشنامهاته استفاده شده است كه

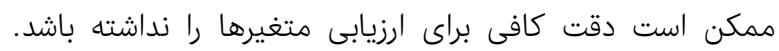

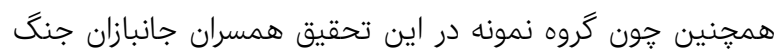

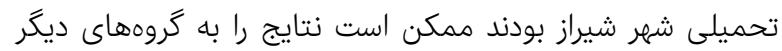

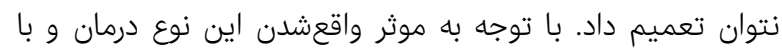

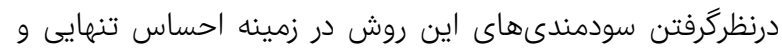

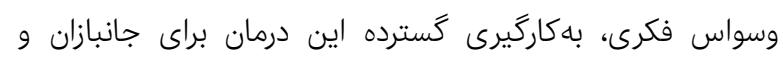

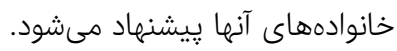


2003;10(2):144-56.

11- Teasdale RD, Matheson F, Gleeson PA. Posttranslational modifications distinguish cell surface from Golgi-retained $\beta 1,4$ galactosyltransferase molecules. Golgi localization involves active retention. Glycobiology. 1994;4(6):917-28.

12- Zarnaqhash M, Mehrabizadeh Honarmand M, Beshlideh K, Davoodi I, Marashi SA. The effectiveness of mindfulness-based stress reduction on quality of life and resiliency of veterans spouses in Ahvaz. Psychol Methods Models. 2016;7(23):83-99. [Persian]

13- DiTommaso E, Brannen C, Best LA. Measurement and validity characteristics of the short version of the social and emotional loneliness scale for adults. Educ Psychol Meas. 2004;64(1):99-119.

14- DiTommaso E, Brannen-McNulty C, Ross L, Burgess M. Attachment styles, social skills and loneliness in young adults. Pers Individ Differ. 2003;35(2):303-12.

15- Rosenzweig S, Greeson JM, Reibel DK, Green JS, Jasser SA, Beasley D. Mindfulness-based stress reduction for chronic pain conditions: variation in treatment outcomes and role of home meditation practice. J Psychosom Res. 2010;68(1):29-36.

16- DiTommaso E, Fizell SR, Robinson BA. Chronic loneliness within an attachment framework: processes and interventions. In: Sha'ked A, Rokach A, editors. Addressing loneliness: coping, prevention and clinical interventions. London: Psychology Press; 2015. p. 263-76. 17- Nolen-Hoeksema S. Responses to depression and their effects on the duration of depressive episodes. J Abnorm Psychol. 1991;100(4):569-82.

18- Perestelo-Perez L, Barraca J, Peñate $W$, RiveroSantana A, Alvarez-Perez Y. Mindfulness-based interventions for the treatment of depressive rumination: systematic review and meta-analysis. Int J Clin Health Psychol. 2017;17(3):282-95.

19- Fili A, Borjali A, Sohrabi F, Farrokhi N. The comparitive efficacy of cognitive- behavior therapy and Teasdale mindfulness-based cognitive therapy of infertile depressed women's rumination. Armaghan-e Danesh. 2012;17(1):14-21. [Persian]

20- Teimouri S, Ramezani F, Mahjoob, N. The effectiveness of mindfulness-based group cognitive therapy in reducing depression and obsessive rumination among women under methadone treatment. J Res Addict. 2015;9(34):145-59. [Persian]

21- Heydarian A, Zahrakar K, Mohsenzadeh F. The effectiveness of mindfulness training on reducing rumination and enhancing resilience in female patients with breast cancer: a randomized trial. Iran J Breast Dis. 2016;9(2):52-9. [Persian]

22- Dianeti F, Moheb N. Effectiveness of mindfulnessbased cognitive therapy on reducing negative strategies of cognitive emotion regulation in patients with obsessive-compulsive disorder. J Instruct Eval. 2018;10(40):171-88. [Persian]

23- Tarkhan M. The influence of mindfulness-based cognitive therapies on loneliness feeling and shyness of students. Soc Cogn. 2017;5(2):94-106. [Persian]

24- Zhang N, Fan FM, Huang SY, Rodriguez MA Mindfulness training for loneliness among Chinese college students: a pilot randomized controlled trial. Int J Psychol. 2018;53(5):373-8.

25- Farhadi A, Movaohdi Y, Kariminejad K, Movahedi M. The effect of mindfulness-based cognitive therapy on depression in male patients with coronary artery disease. J Cardiovasc Nurs. 2014;2(4):6-14. [Persian]
ييشنهاد مىشود در مطالعات آتى همين مدرنى مداخله درمانى با

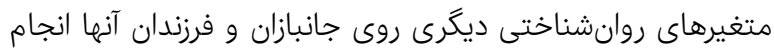

$$
\begin{aligned}
& \text { نتيجه گيرى } \\
& \text { شناختدرمانى مبتنى بر ذهن آكاهى باعث كاهش احساس تنهايى } \\
& \text { و وسواس فكرى همسران جانبازان مى شودانئ. }
\end{aligned}
$$

تشكر و قدردانى: از همكارى و همراهى صميمانه بنياد شهيد و مركز

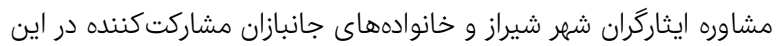

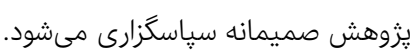

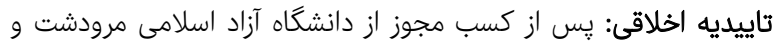

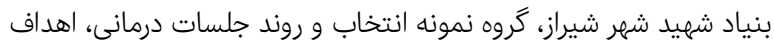

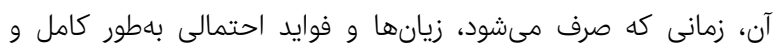

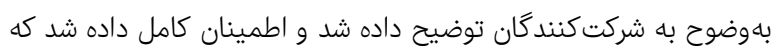

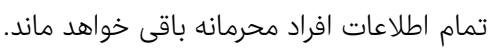

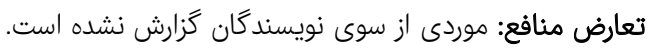

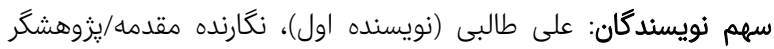

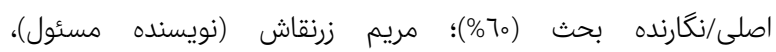

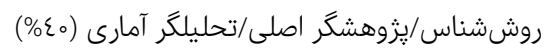

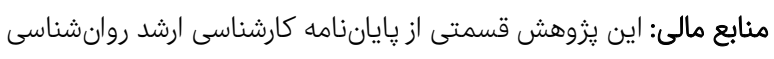

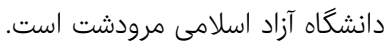

منابع

1- Yahyazadeh H, Masoumzadeh N. Studing the issues of veteran's wives life. J Soc Dev Welfare Plann. 2016;7(28):91-115. [Persian]

2- Eitinger L, Strom A. Mortality and morbidity after excessive stress: a follow-up investigation of Norwegian concentration camp survivors. $1^{\text {st }}$ Edition. New York: Humanities Press; 1973.

3- Harel A, Kahana B, Wilson JP. War and remmembrence. In: Wilson JP, Raphael B, editors. International handbook of traumatic stress syndromes. New York: Springer; 1993. p. 263-74.

4- Khaghanizadeh M, Maleki H, Abbasi M, Abbaspour A, Heshmati Nabavi F, Ebadi A, et al. Elements and structure of medical ethics curriculum. Med Ethics J. 2010;4(12):11-38. [Persian]

5- Vafaei T, Khosravi S. The comparison between mental health of devotee's spouses and normal people's spouses. Iran J War Public Health. 2009;1(4):9-13. [Persian] 6-Yamininia N. Investigation of personality traits of wives of spinal cord and nerves and spouses of harmless individuals [Dissertation]. Tehran: Tarbiat Moalem University; 2001. [Persian]

7- Salimi H, Azad Marzabadi E, Amiri M, Taghavi MR. Aspects of marital satisfaction among veterans' wives. New Thoughts Educ. 2009;4(4):55-72. [Persian]

8- Baer RA. Mindfulness training as a clinical intervention: a conceptual and empirical review. Clin Psychol Sci Pract. 2003;10(2):125-43.

9- Mohammadkhani P, Khanipour H. Mindfulness-based treatments. $1^{\text {st }}$ Edition. Tehran: University of social welfare and rehabilitation sciences; 2011. [Persian] 10- Kabat-Zinn J. Mindfulness-based interventions in context: past, present, and future. Clin Psychol Sci Pract. 